\title{
1 Increasing cellular radioresistance by simultaneous 2 CRISPR/dCas9-driven overexpression of XPC and 3 HR23B genes
}

4 Ilya Velegzhaninov ${ }^{1,2, *}$, Yana Pylina ${ }^{1}$, Anna Rybak ${ }^{1}$, Dmitry Shadrin ${ }^{1}$, Elena Belykh ${ }^{1}$ and Dmitry Klokov ${ }^{3}$

1 Institute of Biology of Komi Science Centre of Ural Branch of RAS, Syctyvkar, Russia; yanapylina@yandex.ru (Ya.P.); canewa.anuta@yandex.ru (A.R.), shdimas@yandex.ru (D.Sh.), daryd22@gmail.com (E.B.)

2 Vyatka State University, Kirov, Russia

3 University of Ottawa, Ottawa, Ontario, Canada; dklokov@uottawa.ca

* Correspondence: vellio@yandex.ru; Tel.: +7-909-121-9693

11 Abstract: Current understanding of mechanisms of cellular resistance to genotoxic stress is incomplete but is critical for a variety of medical applications. Recent developments in the CRISPR/Cas technologies open new opportunities for targeted interrogation of resistance genes and pathways. In the present work, we used nuclease dead Cas9 constructs to achieve targeted overexpression of endogenous genes encoding two essential subunits of DNA damage sensor complex, XPC and HR23B, in HEK293T cells. Both individual and simultaneous overexpression of the two genes was achieved and the effects on cellular resistance to ionizing radiation and paraquat was examined. Using the fluorometric microculture cytotoxicity assay, we showed that simultaneous, but not separate overexpression of the two genes lead to a $30 \%$ increase in survivability. Irradiated cells that overexpressed both XPC and HR23B genes showed higher clonogenic capacity and proliferation rate compared to the irradiated transfection control as revealed by the clonogenic survival assay. Modulation of the gene expression did not affect cell resistance to paraquat. In summary, our results demonstrate a high potential of CRISPR/dCas9enabled multiplex overexpression of stress-response genes in functionally justified combinations, exemplified here by the XPC-HR23B complex, for achieving an enhanced cellular radioresistance.

Keywords: radioresistance; DNA-damage recognition; CRISPRa; multiplex overexpression

\section{Introduction}

Mechanisms triggered in response to genotoxic stress in mammalian cells define cellular resistance to such stress factors. Understanding the mechanisms governing genome integrity and the possibility of their manipulation and regulation have been the focus of biological research in recent decades. This is due to the high fundamental and applied value of such knowledge. Indeed, the mechanisms maintaining genome stability under normal conditions or under the influence of stress factors are closely associated with the mechanisms involved in aging, carcinogenesis and evolution [1-3]. The ability to control the resistance of cells and organisms to genotoxic stress will be of great importance for improving cancer therapies, extending human longevity, creating more stable cellsproducers of recombinant therapeutic proteins and new agricultural plant varieties and breeds of animals, and also for protecting astronauts from cosmic radiation during prospective manned deep space expeditions.

Recent discoveries and developments in CRISPR/Cas genome editing [4,5] and transcription programming (CRISPRa and CRISPRi) [6-11] technologies open vast opportunities in controlling a wide variety of cellular functions, including resistance to genotoxic factors, such as ionizing radiation [12]. In this regard, it can be assumed that a gain-of-function approach would be more promising for studying and achieving the goal of enhancing stress resistance than a loss-of-function approach. First, knocking down stress response genes to lower cell resistance to stress does not automatically mean 
directly enhance stress resistance may have side effects since most genes, especially regulators of gene expression, are involved in multiple, often non-related cellular pathways and functions [13]. Lastly, off-targeted [14] and on-targeted [15] side effects of gene-editing involving were reported, as well as preferential selection of gene-edited cells containing aberrant p53-regulated pathways [16,17]. Previously, we carried out systemic analysis of published literature with respect to modulation of stress resistance by overexpression of different genes [12]. Approximately at the same time, the first works were published in which the CRISPR activation (CRISPRa) screening was performed to find genes, overexpression of which leads to resistance to chemotherapeutic drugs [18,19]. But in our opinion, a wide variety of possible mechanisms for the development of resistance to genotoxic stresses [12] will not allow as to effectively identify all regulatory possibilities by the screening approach. It is necessary to conduct simultaneous focused researches based on known functions and interaction of products of specific genes. Moreover, obviously that achieving an increased stress resistance must not disturb the pathways involved in anticancer mechanisms, such as apoptosis or stress-induced cell senescence. With this in mind, precision overexpression of genes that play a role in the prevention, recognition and repair of DNA damage seems most promising.

Most molecular mechanisms of maintaining the genome stability are based on the simultaneous or sequential operation of multiple proteins and their complexes [20,21], therefore making overexpression of individual genes less likely to be effective compared to simultaneous activation of two and more genes. To this end, CRISPRa technology provided unprecedented opportunities to study the regulation of the cellular resistance to stress factors. In particular, using transcription activators fused to nuclease dead Cas9 (dCas9), the feasibility of targeted adjustable simultaneous overexpression of several genes in their natural chromatin and chromosome context, including all splice-variants, was compellingly demonstrated [8].

In the present work, using the CRISPRa technology, we performed a targeted activation of two DNA damage recognition genes, XPC and $H R 23 B$, either separately or simultaneously, to examine the effect of such manipulation on cellular resistance to ionizing radiation or paraquat. These two genes were selected for this study based on their established role and mode of action during the first stage of recognition of single-stranded DNA damage of various types [22]. The products of the genes work as a complex, with the HR23B protein stabilizing XPC, enabling its binding to damaged DNA $[23,24]$, and rapidly dissociating from XPC thereafter [25]. Another protein, Centrin 2 (CETN2), is also part of a complex that scans DNA for single-stranded lesions. However (CETN2) is not essential for function of the complex since it only facilitates the binding of the XPC complex to DNA, but does not stabilize the complex [26]. Based on this previous knowledge, we hypothesized that increasing the efficiency of DNA damage recognition would require simultaneous overexpression of XPC and $H R 23 B$ genes. Such knowledge-based designed approach for the enhancement of cellular resistance to stress, to our knowledge, has not been used previously in contrast to genome-wide screening approaches.

\section{Materials and Methods}

\subsection{Cells and plasmids}

The experiments were performed using a HEK293T cell line. The cells were maintained in OptiMEM medium (Gibco, Thermo Fisher Scientific, USA) supplemented with $5 \%$ fetal bovine serum (HyClone, Thermo Scientific, USA) without antibiotics at $37^{\circ} \mathrm{C}$ in a $5 \% \mathrm{CO}_{2}$ and $95 \%$ air atmosphere. For dCas9-VPR expression the pXPR_120 plasmid was used which was a gift from John Doench \& David Root (Addgene plasmid \# 96917) [27]. Oligonucleotides coding sgRNA were cloned into the gRNA Cloning Vector Bbs I ver. 2 which was a gift from Hodaka Fujii (Addgene plasmid \# 85586) [28]. 


\section{2. sgRNA design and cloning}

Sequences of sgRNA targeting the promotors of the XPC and HR23B genes (1-400 nucleotides upstream of the transcription start site) were designed and selected using the Casdesigner and Casoffinder online tools [29,30] (Table 1). Synthesis of oligonucleotides for cloning in the gRNA Cloning Vector Bbs I ver. 2 was carried at Evrogen facilities (Russia). Cloning was performed with the restriction enzyme BbsI-HF (New England Biolabs, USA) and the T4 ligase (Evrogen, Russia).

Table 1. Sequences of gRNA targeting the promotors of XPC and HR23B

\begin{tabular}{ccc}
\hline Gene & $\begin{array}{c}\text { Position relative to } \\
\text { transcription start site }\end{array}$ & Sequence 5' $^{\prime} \mathbf{3}^{\prime}$ \\
\hline XPC & -106 & GTATTGTATCCTCACGTTTC \\
& -148 & GTTCTCGCGAGAGGCGGGAA \\
HR23B & -349 & GGCCTACGGCAAAATTCGGA \\
& -123 & GGAACGCGCCTGCGTAATCC \\
& -221 & GGGCGGAGCCTGCACAGAGG \\
& -249 & GGCTACACATTGCGTAACTT \\
\hline
\end{tabular}

\subsection{Transfection and irradiation}

Transfection was performed in a 24-well plate using Lipofectamine 3000 (Invitrogen, USA) according to the manufacturer's protocol. Five hundred nanograms of the pXPR 120 plasmid and 500 ng of an appropriate sgRNA plasmid mixture was used per one well. The efficiency of transfection was $>80 \%$ as controlled by co-transfecting with the eGFP expressing LeGO-G2 vector (a gift from Boris Fehse (Addgene plasmid \#25917)) [31]. Forty-eight hours after transfection the cells were trypsinized and transferred to 96-well plates for the analysis of survivability by the fluorometric microculture cytotoxicity assay (FMCA, 2000 cells/well), in 12-well plates for the clonogenic survival assay (50 or 200 cells/well) or in $60 \mathrm{~mm}$ Petri dishes for the assessment of the proliferation rate (200 or 1000 cells/dish). An aliquot of cell suspension at this point was used for RNA extraction and gene expression analysis. Cells were allowed to adhere to cell culture plastic surfaces for $4 \mathrm{~h}$ and then irradiated with 1, 2, 3, 4 or 6 Gy of gamma-radiation $\left({ }^{60} \mathrm{Co}, 0.73 \mathrm{~Gy} / \mathrm{min}\right)$ for the FMCA or $3 \mathrm{~Gy}$ only for clonogenic survival assay. In a separate experiment, cells were treated with $100 \mu \mathrm{M}$ paraquat in the growth medium. In 12-well plates and Petri dishes, the medium with paraquat was replaced by fresh paraquat-free medium after $24 \mathrm{~h}$ of incubation. Cells in a 96-well plate were kept in the medium with paraquat until analysis. For each plating format and variant of transfection one's own control was prepared from same cell suspension as all variant of treatment.

\subsection{Analysis of survival and proliferation}

Radioresistance was estimated using two different methods and in two independent experiments, separated in time: one was the FMCA measuring the fraction of surviving cells [32] and the other was the conventional clonogenic survival assay [33,34]. The survival of cells with and without overexpression of XPC and HR23B was analyzed $72 \mathrm{~h}$ after irradiation or the start of a paraquat treatment using the FMCA [32]. The results were expressed and statistically analyzed as mean fluorescence of 24 (for irradiation) or 12 (for paraquat) replicates (microcultures in separate wells/dishes) relative to the mean value of 24 replicates of untreated control. Each transfection variant had its own untreated control.

For the clonogenic survival assay, cells plated onto 12-well plates were fixed 7 days after treatment and the number of surviving colonies ( $>100$ cells per colony) was scored. The results were expressed and statistically analyzed as mean number of colonies in 12 replicate wells relative to untreated control. 
For assessing the proliferation rate, cells in Petri dishes were fixed 5 days after treatment and 25 colonies were randomly selected from each treatment/transfection group and the number of cells per colony was counted.

Each experiment and plating format had its own control plated from the same cell suspension. In all three cases, the Student t-test with Bonferroni correction was used for comparison between groups.

\section{$2.5 q R T-P C R$}

RNA was extracted using Aurum Total RNA Mini Kit (BioRad, USA) as per manufacturer's instructions. Extracted RNA was quantified using Qubit ${ }^{\mathrm{TM}}$ RNA BR Assay Kit and Qubit ${ }^{\mathrm{TM}}$ fluorometer (Thermo Fisher Scientific, USA). One microgram of total RNA per sample was reverse transcribed into cDNA using Maxima First Strand cDNA Synthesis Kit (Thermo Fisher Scientific, USA) as per manufacturer's recommendations. The real time PCR reactions were conducted using qPCRmix-HS SYBR (Evrogen, Russia) on a CFX96 PCR Detection System (Bio-Rad, USA). The following PCR cycling conditions were used: $95^{\circ} \mathrm{C}$ for $5 \mathrm{~min}, 40$ cycles of $95^{\circ} \mathrm{C}$ for $15 \mathrm{sec}, 58^{\circ} \mathrm{C}$ for 15 sec and $72^{\circ} \mathrm{C} 30 \mathrm{sec}$. Each analysis was carried out in three technical replicates. Relative expression was calculated using the $\triangle \triangle C$ t method [35] by normalizing to the house keeping genes $A C T B$ and GAPDH. Data were analyzed using CFX Manager (Bio-Rad, USA) and Excel (Microsoft, USA) software. Primers for XPC and HR23B were designed using Primer-BLAST online tool [36] (XPCforward - TGGGTCGTACCTCTGTGTGA, XPC-reverse - ATGTGCAGCGATGGTGAGAA, HR23Bforward - ACAACTCAGCAGTCAGCTCC, HR23B-reverse - AGTGATGGATGCAGGTGTGG). Primer sequences for GAPDH were taken from Cheng et al. [37] (forward ACACCCACTCCTCCACCTTTG, reverse - GCTGTAGCCAAATTCGTTGTCATAC), and for ACTB from Ding et al. [38] (forward - GCGCGGCTACAGCTTCA, reverse CTTAATGTCACGCACGATTTCC). Oligonucleotides were synthesized by Evrogen (Russia).

\section{Results and discussion}

The HEK293T cells were transfected with a plasmid encoding dCas9 with the VPR activator and plasmids for the expression of the sgRNA. Forty-eight hours after transfection, cells were split and one part was used for gene expression analysis, whereas the other parts were irradiated with various doses of radiation $(1,2,3,4$ or 6 Gy) or treated with paraquat (100 $\mu \mathrm{M}$ in culture medium). Seventytwo hours after irradiation or the addition of paraquat, the survival of cells was assessed using the FMCA. In separate experiments, both the clonogenic survival and the proliferation rate were measured after irradiation at $3 \mathrm{~Gy}$ as described in Materials and Methods.

When the described CRISPRa method targeted the expression of XPC alone, a three-fold overexpression of the gene was observed (Fig. 1A). This however resulted in a slight decrease in the resistance of cells to ionizing radiation and did not affect the resistance to paraquat (Fig. 1B). It is known that overexpression of XPC leads to an increase in the resistance of human colorectal cancer SW480 cells to cisplatin [39]; however, in vivo studies showed that ubiquitous overexpression of the gene lead to a decrease in the resistance of D. melanogaster to paraquat [40] and did not change the resistance to ionizing radiation [41]. The failure of XPC overexpression to enhance the resistance to genotoxic stress can be explained by the fact that the activity and the stability of the XPC protein depends on HR23B [23,24]. A disruption of the balance of XPC activity not related to DNA repair and independent of HR23B could also be implicated. For example, it was shown that XPC enhances DNA damage induced apoptosis by downregulating the antiapoptotic short isoform of caspase-2 [42]. In addition, XPC is involved in the regulation of transcription, the proteasomal degradation of certain proteins and some other mechanisms (reviewed in [43]).

Targeting the HR23B resulted in a two-fold activation of the gene (Fig 1A). Similar to the XPC activation, this did not improve cellular resistance to irradiation or paraquat treatment. In fact, the survival of cells overexpressing HR23B after the paraquat treatment decreased (Fig. 1C), whereas 
their radioresistance did not change (Fig. 1B). Changes in survivability were measured relative to transfection controls run in every single experiment. $H R 23 B$ is also a multifunctional gene that in addition to recognizing DNA damage is involved in protein degradation and stability, cell cycle control and apoptosis [44].

In experiments where XPC and $H R 23 B$ were targeted simultaneously, the levels of achieved overexpression were 4- and 2.5-fold, respectively (Fig, 1A). Cells with both genes overexpressed showed an increased survival after irradiation at all tested doses (1, 2, 3, 4 and 6 Gy) (Fig. 1B). The resistance to the paraquat treatment also increased (Fig 1C). In order to verify the obtained results, as well as to measure changes in cell proliferation, we partially repeated the experiments using the clonogenic survival assay on cells exposed to a 3 Gy radiation dose. Similar to the first set of experiments, a significant overexpression of both XPC and HR23B was achieved (Fig. 2A). These cells were again radioresistant as revealed by the clonogenic survival assay (Fig 2B). However, no alterations in the resistance to paraquat were seen (Fig 2C). The results also showed that radiation induced suppression of proliferation occurred to a lesser extent in the cells overexpressing XPC and HR23B compared to the transfecteion control (dCas9-VPR alone). Importantly, the basal level of proliferation was not altered by the overexpression of XPC and HR23B (Fig 2D).

It is most feasible to assume that the enhanced radioresistance in our experiments was the result of an increased efficiency of DNA damage recognition by the XPC-HR23B complex. Yet, other functions of the complex may have contributed to the enhanced resistance to genotoxic stress. For example, the complex can activate 8-oxoguanine DNA glycosylase (OGG1) [45], whose overexpression can improve the sustainability of Chinese hamster ovary cell lines to oxidative stress [46]. The ability of the XPC-HR23B complex to promote the MDM2-mediated degradation of the p53 tumor suppressor [47] can also contribute to cell survival. On the other hand, however, overexpression of XPC could stimulate DNA damage induced apoptosis [42].

It could be argued that our results demonstrating the enhancement of radioresistance by simultaneous, but not separate, overexpression of XPC and HR23B are not consistent with the studies indicating that HR23B protein is expressed in excess relative to XPC [26,48,49]. In this case one would expect that the overexpression of XPC alone should suffice for enhancing radioresistance. However, it is known that the regulation of HR23B activity is maintained by controlling its intracellular distribution. Thus, progestin and adipoQ receptor family member 3 (PAQR3) can sequester HR23B in the Golgi apparatus, reducing the protein level in the nucleus and, accordingly, its binding to XPC [50]. Moreover, intracellular distribution of HR23B is cell cycle dependent [51]. It would seem feasible to assume that overexpression of XPC would not affect the localization of HR23B, whereas overexpression of the latter would result in higher levels of the protein in all corresponding cellular compartments
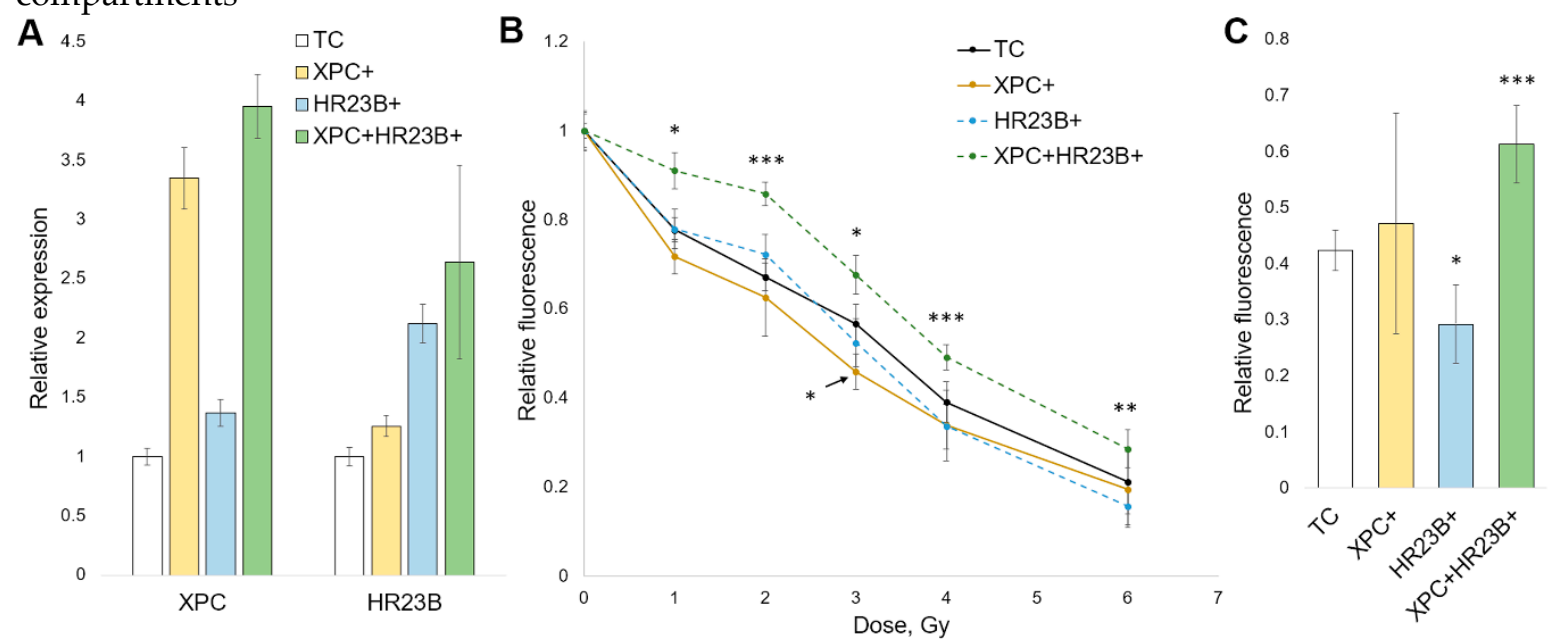

Figure 1. Simultaneous, but not individual, overexpression of XPC and HR23B genes enhance survivability of HEK293T cells after treatment with ionizing radiation or paraquat. A, Quantification of the expression of XPC and HR23B in cells transfected with dCas9-VPR activator and sgRNA targeting the XPC and HR23B promoters 
in various combinations relative to cells transfected with the dCas9-VPR activator alone (transcription control or TC). The mean values of three independent experiments are presented. B, survivability of the cells transfected as in A after gamma-irradiation with 1, 2, 3, 4 and 6 Gy relative to non-irradiated control. The mean values for 24 replicates per data point are presented. C, survivability of the cells transfected as in A after treatment with $100 \mu \mathrm{M}$ paraquat relative to untreated control. The mean values for 12 microcultures per data point are presented. ${ }^{* * *}$ and ${ }^{* * *}$ indicate the difference between marked groups at $\mathrm{p}<0.05, \mathrm{p}<0.01$ and $\mathrm{p}<0.001$, respectively (t-Student test with Bonferroni correction).
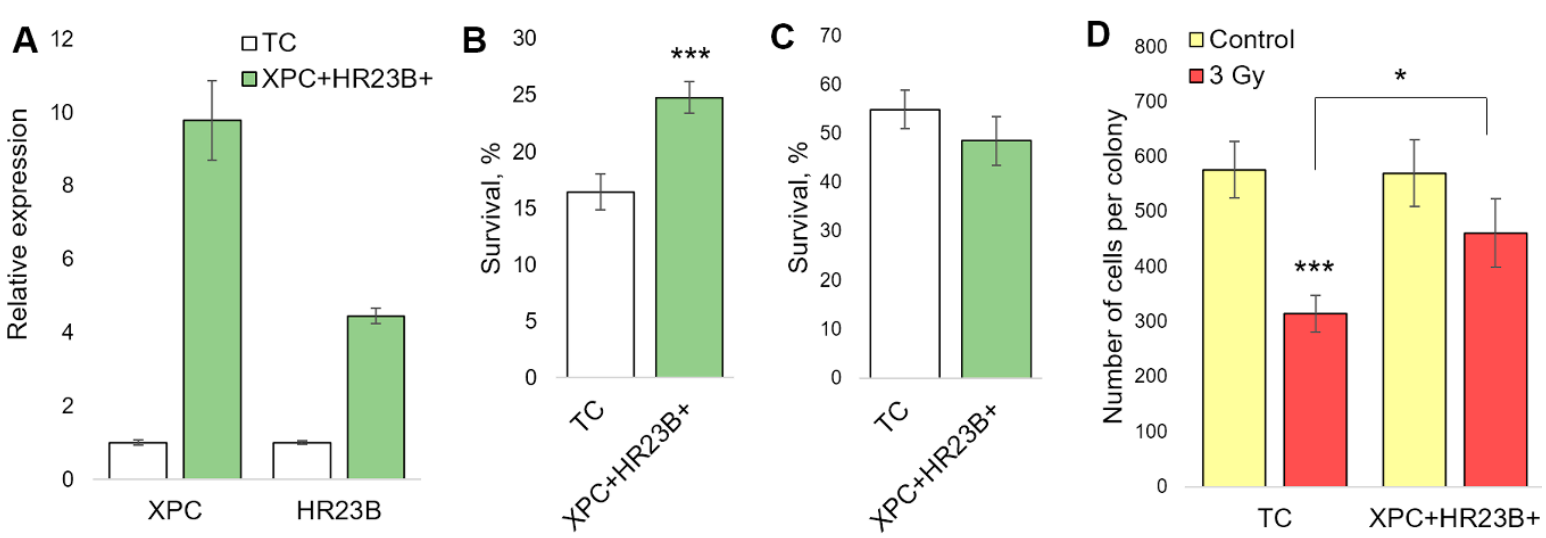

Figure 2. Simultaneous, but not individual, overexpression of XPC and HR23B genes enhance clonogenic survivability of HEK293T cells after treatment with ionizing radiation. A, Quantification of the expression of XPC and HR23B in cells transfected with dCas9-VPR activator and gRNA targeting the XPC and HR23B promoters in various combinations relative to cells transfected with the dCas9-VPR activator alone (transcription control or TC). The mean values of three independent experiments are presented. Clonogenic survivability of the cells transfected as in A and exposed to gamma-irradiation with $3 \mathrm{~Gy}$ (B) or $100 \mathrm{mM}$ paraquat (C) relative to non-irradiated control. The mean values for 12 replicates per data point are presented. $\mathrm{D}$, The proliferation rate of the cells transfected as in A, expressed as the number of cells per colony 5 days after irradiation with $3 \mathrm{~Gy}$. *, ${ }^{* * *}$ indicate the difference between marked groups at $\mathrm{p}<0.05$ and $\mathrm{p}<0.001$, respectively (t-Student test with Bonferroni correction).

One important question that remains to be answered is whether the increase in radioresistance in XPC and HR23B overexpressing cells is due to or can lead to the imbalance of the defense systems protecting the cell from neoplastic transformation and malignancy. Presently, this possibility cannot be ruled out because the functions of the XPC-HR23B complex are not limited to the DNA damage recognition alone. As mentioned above, the complex can promote the MDM2-mediated degradation of the p53 protein [47]. Several studies have suggested the role of the XPC-HR23B-CETN2 complex in maintaining the pluripotency of stem cells through interaction with Oct4/Sox2 [52,53], whose role in cancer stem cells was suggested [54]. However, this issue remains controversial, since the removal of the C-terminal region of XPC, including the sites interacting with HR23B and CETN2, had little impact on the transcriptional activity of Oct3/4 [55]. Nevertheless, based on the results of loss-offunction studies, the enhancement of the main function of the XPC complex related to DNA damage recognition is expected to suppress the probability of carcinogenesis. Thus, the deficiency of the XPC function leads to the tremendously higher rates of cancer incidence in people with Xeroderma pigmentosum [56]. Similar observations were made in mouse studies [57-62]. Lastly, consistent with the suggestion of the lack of carcinogenic risk upon XPC and HR23B overexpression, $H R 23 B$ was found to be expressed at substantially lower levels in highly invasive breast cancer cell lines compared to the low-invasive ones [63].

\section{Conclusions}

In summary, our results demonstrate a high potential of CRISPR/dCas9-enabled multiplex overexpression of stress-response genes in functionally justified combinations, exemplified here by 
the XPC-HR23B complex, for achieving an enhanced cellular radioresistance. A higher resistance to other oxidative stress factors is also feasible. This approach has several arguable advantages in studying the mechanisms of the regulation of cell stress resistance over the approaches based on lossof-function methods, including the genome screening knock-out studies that are gaining popularity. Importantly, the presented method allows overexpression of selected stress-response genes in their natural chromosomal context ensuring relevant and artefact free results.

Author Contributions: Conceived and designed the experiments: I.V. Performed the experiments: I.V., D.Sh., Ya.P., E.B., A.R. Analyzed and interpreted the data: I.V., D.K. Wrote the manuscript: I.V., D.K.

Funding: The study was supported by a Grant of the President of the Russian Federation (MK-2929.2017.4).

Acknowledgments: We thank Anton Yudin, Lisa Pnachina, Lisa Fefilova and Lada Noskova for the blind counting of colonies and cells in clonogenic survival assay. The work was done using the equipment of the Center of Collective Usage (CCU) "Molecular Biology", the Institute of Biology of the Komi Science Centre of the Ural Division RAS.

Conflicts of Interest: The authors declare no conflict of interest

\section{References}

1. Vijg, J.; Suh, Y. Genome Instability and Aging. Annual Review of Physiology 2013, 75, 645-668, doi:10.1146/annurev-physiol-030212-183715.

2. Jeggo, P. A.; Pearl, L. H.; Carr, A. M. DNA repair, genome stability and cancer: a historical perspective. Nature Reviews Cancer 2016, 16, 35-42, doi:10.1038/nrc.2015.4.

3. Schubert, I.; Vu, G. T. H. Genome Stability and Evolution: Attempting a Holistic View. Trends in Plant Science 2016, 21, 749-757, doi:10.1016/j.tplants.2016.06.003.

4. Gasiunas, G.; Barrangou, R.; Horvath, P.; Siksnys, V. Cas9-crRNA ribonucleoprotein complex mediates specific DNA cleavage for adaptive immunity in bacteria. Proceedings of the National Academy of Sciences 2012, 109, E2579-E2586, doi:10.1073/pnas.1208507109.

5. Jinek, M.; Chylinski, K.; Fonfara, I.; Hauer, M.; Doudna, J. A.; Charpentier, E. A Programmable Dual-RNAGuided DNA Endonuclease in Adaptive Bacterial Immunity. Science 2012, 337, 816-821, doi:10.1126/science.1225829.

6. Gilbert, L. A.; Larson, M. H.; Morsut, L.; Liu, Z.; Brar, G. A.; Torres, S. E.; Stern-Ginossar, N.; Brandman, O.; Whitehead, E. H.; Doudna, J. A.; Lim, W. A.; Weissman, J. S.; Qi, L. S. CRISPR-mediated modular RNAguided regulation of transcription in eukaryotes. Cell 2013, 154, 442-451, doi:10.1016/j.cell.2013.06.044.

7. Maeder, M. L.; Linder, S. J.; Cascio, V. M.; Fu, Y.; Ho, Q. H.; Joung, J. K. CRISPR RNA-guided activation of endogenous human genes. Nat. Methods 2013, 10, 977-979, doi:10.1038/nmeth.2598.

8. Chavez, A.; Scheiman, J.; Vora, S.; Pruitt, B. W.; Tuttle, M.; P R Iyer, E.; Lin, S.; Kiani, S.; Guzman, C. D.; Wiegand, D. J.; Ter-Ovanesyan, D.; Braff, J. L.; Davidsohn, N.; Housden, B. E.; Perrimon, N.; Weiss, R.; Aach, J.; Collins, J. J.; Church, G. M. Highly efficient Cas9-mediated transcriptional programming. Nat. Methods 2015, 12, 326-328, doi:10.1038/nmeth.3312.

9. Hilton, I. B.; D’Ippolito, A. M.; Vockley, C. M.; Thakore, P. I.; Crawford, G. E.; Reddy, T. E.; Gersbach, C. A. Epigenome editing by a CRISPR-Cas9-based acetyltransferase activates genes from promoters and enhancers. Nat. Biotechnol. 2015, 33, 510-517, doi:10.1038/nbt.3199.

10. Klann, T. S.; Black, J. B.; Chellappan, M.; Safi, A.; Song, L.; Hilton, I. B.; Crawford, G. E.; Reddy, T. E.; Gersbach, C. A. CRISPR-Cas9 epigenome editing enables high-throughput screening for functional regulatory elements in the human genome. Nat. Biotechnol. 2017, 35, 561-568, doi:10.1038/nbt.3853. 
11. Larson, M. H.; Gilbert, L. A.; Wang, X.; Lim, W. A.; Weissman, J. S.; Qi, L. S. CRISPR interference (CRISPRi) for sequence-specific control of gene expression. Nature Protocols 2013, 8, 2180-2196, doi:10.1038/nprot.2013.132.

12. Velegzhaninov, I. O.; Ievlev, V. A.; Pylina, Y. I.; Shadrin, D. M.; Vakhrusheva, O. M. Programming of Cell Resistance to Genotoxic and Oxidative Stress. Biomedicines 2018, 6, doi:10.3390/biomedicines6010005.

13. Copley, S. D. Moonlighting is mainstream: Paradigm adjustment required. BioEssays 2012, 34, 578-588, doi:10.1002/bies.201100191.

14. Zhang, X.-H.; Tee, L. Y.; Wang, X.-G.; Huang, Q.-S.; Yang, S.-H. Off-target Effects in CRISPR/Cas9mediated Genome Engineering. Molecular Therapy - Nucleic Acids 2015, 4, e264, doi:10.1038/mtna.2015.37.

15. Kosicki, M.; Tomberg, K.; Bradley, A. Repair of double-strand breaks induced by CRISPR-Cas9 leads to large deletions and complex rearrangements. Nature Biotechnology 2018, doi:10.1038/nbt.4192.

16. Ihry, R. J.; Worringer, K. A.; Salick, M. R.; Frias, E.; Ho, D.; Theriault, K.; Kommineni, S.; Chen, J.; Sondey, M.; Ye, C.; Randhawa, R.; Kulkarni, T.; Yang, Z.; McAllister, G.; Russ, C.; Reece-Hoyes, J.; Forrester, W.; Hoffman, G. R.; Dolmetsch, R.; Kaykas, A. p53 inhibits CRISPR-Cas9 engineering in human pluripotent stem cells. Nature Medicine 2018, 24, 939-946, doi:10.1038/s41591-018-0050-6.

17. Urnov, F. D. A path to efficient gene editing. Nature Medicine 2018, 24, 899-900, doi:10.1038/s41591-0180110-y.

18. le Sage, C.; Lawo, S.; Panicker, P.; Scales, T. M. E.; Rahman, S. A.; Little, A. S.; McCarthy, N. J.; Moore, J. D.; Cross, B. C. S. Dual direction CRISPR transcriptional regulation screening uncovers gene networks driving drug resistance. Scientific Reports 2017, 7, doi:10.1038/s41598-017-18172-6.

19. Bester, A. C.; Lee, J. D.; Chavez, A.; Lee, Y.-R.; Nachmani, D.; Vora, S.; Victor, J.; Sauvageau, M.; Monteleone, E.; Rinn, J. L.; Provero, P.; Church, G. M.; Clohessy, J. G.; Pandolfi, P. P. An Integrated Genome-wide CRISPRa Approach to Functionalize lncRNAs in Drug Resistance. Cell 2018, 173, 649664.e20, doi:10.1016/j.cell.2018.03.052.

20. Sugasawa, K. Molecular mechanisms of DNA damage recognition for mammalian nucleotide excision repair. DNA Repair 2016, 44, 110-117, doi:10.1016/j.dnarep.2016.05.015.

21. Sancar, A.; Lindsey-Boltz, L. A.; Unsal-Kaçmaz, K.; Linn, S. Molecular mechanisms of mammalian DNA repair and the DNA damage checkpoints. Annu. Rev. Biochem. 2004, 73, 39-85, doi:10.1146/annurev.biochem.73.011303.073723.

22. Thoma, B. S.; Vasquez, K. M. Critical DNA damage recognition functions of XPC-hHR23B and XPA-RPA in nucleotide excision repair. Molecular Carcinogenesis 2003, 38, 1-13, doi:10.1002/mc.10143.

23. Batty, D.; Rapic'-Otrin, V.; Levine, A. S.; Wood, R. D. Stable binding of human XPC complex to irradiated DNA confers strong discrimination for damaged sites 1 1Edited by M. Yaniv. Journal of Molecular Biology 2000, 300, 275-290, doi:10.1006/jmbi.2000.3857.

24. Okuda, Y.; Nishi, R.; Ng, J. M. Y.; Vermeulen, W.; van der Horst, G. T. J.; Mori, T.; Hoeijmakers, J. H. J.; Hanaoka, F.; Sugasawa, K. Relative levels of the two mammalian Rad23 homologs determine composition and stability of the xeroderma pigmentosum group C protein complex. DNA Repair 2004, 3, 1285-1295, doi:10.1016/j.dnarep.2004.06.010.

25. Bergink, S.; Toussaint, W.; Luijsterburg, M. S.; Dinant, C.; Alekseev, S.; Hoeijmakers, J. H. J.; Dantuma, N. P.; Houtsmuller, A. B.; Vermeulen, W. Recognition of DNA damage by XPC coincides with disruption of the XPC-RAD23 complex. The Journal of Cell Biology 2012, 196, 681-688, doi:10.1083/jcb.201107050. 
340 26. Nishi, R.; Okuda, Y.; Watanabe, E.; Mori, T.; Iwai, S.; Masutani, C.; Sugasawa, K.; Hanaoka, F. Centrin 2 Stimulates Nucleotide Excision Repair by Interacting with Xeroderma Pigmentosum Group C Protein. Molecular and Cellular Biology 2005, 25, 5664-5674, doi:10.1128/MCB.25.13.5664-5674.2005.

27. Najm, F. J.; Strand, C.; Donovan, K. F.; Hegde, M.; Sanson, K. R.; Vaimberg, E. W.; Sullender, M. E.; Hartenian, E.; Kalani, Z.; Fusi, N.; Listgarten, J.; Younger, S. T.; Bernstein, B. E.; Root, D. E.; Doench, J. G. Orthologous CRISPR-Cas9 enzymes for combinatorial genetic screens. Nat. Biotechnol. 2018, 36, 179-189, doi:10.1038/nbt.4048.

28. Fujita, T.; Yuno, M.; Fujii, H. Allele-specific locus binding and genome editing by CRISPR at the p16INK4a locus. Sci Rep 2016, 6, 30485, doi:10.1038/srep30485.

29. Bae, S.; Park, J.; Kim, J.-S. Cas-OFFinder: a fast and versatile algorithm that searches for potential off-target sites of Cas9 RNA-guided endonucleases. Bioinformatics 2014, 30, 1473-1475, doi:10.1093/bioinformatics/btu048.

30. Park, J.; Bae, S.; Kim, J.-S. Cas-Designer: a web-based tool for choice of CRISPR-Cas9 target sites. Bioinformatics 2015, 31, 4014-4016, doi:10.1093/bioinformatics/btv537.

31. Weber, K.; Bartsch, U.; Stocking, C.; Fehse, B. A multicolor panel of novel lentiviral "gene ontology" (LeGO) vectors for functional gene analysis. Mol. Ther. 2008, 16, 698-706, doi:10.1038/mt.2008.6.

32. Lindhagen, E.; Nygren, P.; Larsson, R. The fluorometric microculture cytotoxicity assay. Nat Protoc 2008, 3, 1364-1369, doi:10.1038/nprot.2008.114.

33. Puck, T. T. ACTION OF X-RAYS ON MAMMALIAN CELLS. Journal of Experimental Medicine 1956, 103, 653-666, doi:10.1084/jem.103.5.653.

34. Rafehi, H.; Orlowski, C.; Georgiadis, G. T.; Ververis, K.; El-Osta, A.; Karagiannis, T. C. Clonogenic Assay: Adherent Cells. Journal of Visualized Experiments 2011, doi:10.3791/2573.

35. Livak, K. J.; Schmittgen, T. D. Analysis of relative gene expression data using real-time quantitative PCR and the 2(-Delta Delta C(T)) Method. Methods 2001, 25, 402-408, doi:10.1006/meth.2001.1262.

36. Ye, J.; Coulouris, G.; Zaretskaya, I.; Cutcutache, I.; Rozen, S.; Madden, T. L. Primer-BLAST: a tool to design target-specific primers for polymerase chain reaction. BMC Bioinformatics 2012, 13, 134, doi:10.1186/14712105-13-134.

37. Cheng, K.-C.; Huang, H.-C.; Chen, J.-H.; Hsu, J.-W.; Cheng, H.-C.; Ou, C.-H.; Yang, W.-B.; Chen, S.-T.; Wong, C.-H.; Juan, H.-F. Ganoderma lucidum polysaccharides in human monocytic leukemia cells: from gene expression to network construction. BMC Genomics 2007, 8, 411, doi:10.1186/1471-2164-8-411.

38. Ding, K.-K.; Shang, Z.-F.; Hao, C.; Xu, Q.-Z.; Shen, J.-J.; Yang, C.-J.; Xie, Y.-H.; Qiao, C.; Wang, Y.; Xu, L.-

L.; Zhou, P.-K. Induced expression of the IER5 gene by gamma-ray irradiation and its involvement in cell cycle checkpoint control and survival. Radiat Environ Biophys 2009, 48, 205-213, doi:10.1007/s00411-0090213-4.

39. Zhang, Y.; Cao, J.; Meng, Y.; Qu, C.; Shen, F.; Xu, L. Overexpression of xeroderma pigmentosum groupi $i_{i}^{1 / 2 C}$ decreases the chemotherapeutic sensitivity of colorectal carcinoma cells to cisplatin. Oncology Letters 2018, doi:10.3892/ol.2018.8127.

40. Shaposhnikov, M.; Proshkina, E.; Shilova, L.; Zhavoronkov, A.; Moskalev, A. Lifespan and Stress Resistance in Drosophila with Overexpressed DNA Repair Genes. Sci Rep 2015, 5, 15299, doi:10.1038/srep15299.

41. Shilova, L. A.; Pliusnina, E. N.; Zemskaia, N. V.; Moskalev, A. A. [Role of DNA repair genes in radiation- 
42. Wang, Q.-E.; Han, C.; Zhang, B.; Sabapathy, K.; Wani, A. A. Nucleotide Excision Repair Factor XPC Enhances DNA Damage-Induced Apoptosis by Downregulating the Antiapoptotic Short Isoform of Caspase-2. Cancer Research 2012, 72, 666-675, doi:10.1158/0008-5472.CAN-11-2774.

43. Nemzow, L.; Lubin, A.; Zhang, L.; Gong, F. XPC: Going where no DNA damage sensor has gone before. DNA Repair 2015, 36, 19-27, doi:10.1016/j.dnarep.2015.09.004.

44. Yokoi, M.; Hanaoka, F. Two mammalian homologs of yeast Rad23, HR23A and HR23B, as multifunctional proteins. Gene 2017, 597, 1-9, doi:10.1016/j.gene.2016.10.027.

45. D’Errico, M.; Parlanti, E.; Teson, M.; de Jesus, B. M. B.; Degan, P.; Calcagnile, A.; Jaruga, P.; Bjørås, M.; Crescenzi, M.; Pedrini, A. M.; Egly, J.-M.; Zambruno, G.; Stefanini, M.; Dizdaroglu, M.; Dogliotti, E. New functions of XPC in the protection of human skin cells from oxidative damage. The EMBO Journal 2006, 25, 4305-4315, doi:10.1038/sj.emboj.7601277.

46. Hollenbach, S.; Dhénaut, A.; Eckert, I.; Radicella, J. P.; Epe, B. Overexpression of Ogg1 in mammalian cells: effects on induced and spontaneous oxidative DNA damage and mutagenesis. Carcinogenesis 1999, 20 , 1863-1868.

47. Krzeszinski, J. Y.; Choe, V.; Shao, J.; Bao, X.; Cheng, H.; Luo, S.; Huo, K.; Rao, H. XPC promotes MDM2mediated degradation of the p53 tumor suppressor. Molecular Biology of the Cell 2014, 25, 213-221, doi:10.1091/mbc.e13-05-0293.

48. Sugasawa, K.; Masutani, C.; Uchida, A.; Maekawa, T.; van der Spek, P. J.; Bootsma, D.; Hoeijmakers, J. H.; Hanaoka, F. HHR23B, a human Rad23 homolog, stimulates XPC protein in nucleotide excision repair in vitro. Molecular and Cellular Biology 1996, 16, 4852-4861, doi:10.1128/MCB.16.9.4852.

49. van der Spek, P. XPC and human homologs of RAD23: intracellular localization and relationship to other nucleotide excision repair complexes. Nucleic Acids Research 1996, 24, 2551-2559, doi:10.1093/nar/24.13.2551.

50. You, X.; Guo, W.; Wang, L.; Hou, Y.; Zhang, H.; Pan, Y.; Han, R.; Huang, M.; Liao, L.; Chen, Y. Subcellular distribution of RAD23B controls XPC degradation and DNA damage repair in response to chemotherapy drugs. Cellular Signalling 2017, 36, 108-116, doi:10.1016/j.cellsig.2017.04.023.

51. Katiyar, S.; Lennarz, W. J. Studies on the intracellular localization of hHR23B. Biochemical and Biophysical Research Communications 2005, 337, 1296-1300, doi:10.1016/j.bbrc.2005.09.192.

52. Liu, L.; Peng, Z.; Xu, Z.; Wei, X. XPC Promotes Pluripotency of Human Dental Pulp Cells through Regulation of Oct-4/Sox2/c-Myc. Stem Cells International 2016, 2016, 1-12, doi:10.1155/2016/3454876.

53. Cattoglio, C.; Zhang, E. T.; Grubisic, I.; Chiba, K.; Fong, Y. W.; Tjian, R. Functional and mechanistic studies of XPC DNA-repair complex as transcriptional coactivator in embryonic stem cells. Proceedings of the National Academy of Sciences 2015, 112, E2317-E2326, doi:10.1073/pnas.1505569112.

54. Sławek, S.; Szmyt, K.; Fularz, M.; Dziudzia, J.; Boruczkowski, M.; Sikora, J.; Kaczmarek, M. Pluripotency transcription factors in lung cancer-a review. Tumour Biol. 2016, 37, 4241-4249, doi:10.1007/s13277-0154407-x.

55. Ito, S.; Yamane, M.; Ohtsuka, S.; Niwa, H. The C-terminal region of Xpc is dispensable for the transcriptional activity of Oct3/4 in mouse embryonic stem cells. FEBS Letters 2014, 588, 1128-1135, doi:10.1016/j.febslet.2014.02.033.

56. Kraemer, K. H.; Lee, M. M.; Scotto, J. Xeroderma pigmentosum. Cutaneous, ocular, and neurologic abnormalities in 830 published cases. Arch Dermatol 1987, 123, 241-250. 
423 57. Sands, A. T.; Abuin, A.; Sanchez, A.; Conti, C. J.; Bradley, A. High susceptibility to ultraviolet-induced carcinogenesis in mice lacking XPC. Nature 1995, 377, 162-165, doi:10.1038/377162a0.

58. Hollander, M. C.; Philburn, R. T.; Patterson, A. D.; Velasco-Miguel, S.; Friedberg, E. C.; Linnoila, R. I.; Fornace, A. J. Deletion of XPC leads to lung tumors in mice and is associated with early events in human lung carcinogenesis. Proceedings of the National Academy of Sciences 2005, 102, 13200-13205, doi:10.1073/pnas.0503133102.

59. Tanaka, K.; Kamiuchi, S.; Ren, Y.; Yonemasu, R.; Ichikawa, M.; Murai, H.; Yoshino, M.; Takeuchi, S.; Saijo, M.; Nakatsu, Y.; Miyauchi-Hashimoto, H.; Horio, T. UV-induced skin carcinogenesis in xeroderma pigmentosum group A (XPA) gene-knockout mice with nucleotide excision repair-deficiency. Mutation Research/Fundamental and Molecular Mechanisms of Mutagenesis 2001, 477, 31-40, doi:10.1016/S00275107(01)00093-8.

60. Friedberg, E. C.; Bond, J. P.; Burns, D. K.; Cheo, D. L.; Greenblatt, M. S.; Meira, L. B.; Nahari, D.; Reis, A. M. Defective nucleotide excision repair in Xpc mutant mice and its association with cancer predisposition. Mutation Research/DNA Repair 2000, 459, 99-108, doi:10.1016/S0921-8777(99)00068-3.

61. Berg, R. J. W.; Ruven, H. J. T.; Sands, A. T.; de Gruijl, F. R.; Mullenders, L. H. F. Defective Global Genome Repair in XPC Mice Is Associated with Skin Cancer Susceptibility But Not with Sensitivity to UVB Induced Erythema and Edema. Journal of Investigative Dermatology 1998, 110, 405-409, doi:10.1111/j.15231747.1998.00173.x.

62. Rezvani, H. R.; Kim, A. L.; Rossignol, R.; Ali, N.; Daly, M.; Mahfouf, W.; Bellance, N.; Taïeb, A.; de Verneuil, H.; Mazurier, F.; Bickers, D. R. XPC silencing in normal human keratinocytes triggers metabolic alterations that drive the formation of squamous cell carcinomas. Journal of Clinical Investigation 2011, 121, 195-211, doi:10.1172/JCI40087.

63. Linge, A.; Maurya, P.; Friedrich, K.; Baretton, G. B.; Kelly, S.; Henry, M.; Clynes, M.; Larkin, A.; Meleady, 